\title{
Growth Factor Modulation of Substrate-Specific Morphological Patterns in Aplysia Bag Cell Neurons
}

\author{
Lore M. Gruenbaum and Thomas J. Carew ${ }^{1}$ \\ Departments of Psychology and Molecular, Cellular, and Developmental Biology \\ Yale University \\ New Haven, Connecticut 06511 USA
}

\section{Abstract}

Components of the extracellular matrix (ECM) can act not only as passive substrates for neuronal attachment and outgrowth but also as active sites for signal transduction. Thus, specific ECM components may modulate effects of growth factors (GFs) that play an important role in structural changes in development and adult neuronal plasticity. In this study we examined the interaction of cultured Aplysia bag cell neurons (BCNs) with components of ECM and different GFs. Different ECM substrata induce a substrate-specific BCN morphology: BCNs grown on collagen or poly-L-lysine have larger soma diameter and more extensive neurite outgrowth than BCNs grown on laminin or fibronectin. BCNs also interact in a substrate-dependent way with GFs: BDNF treatment leads to a reduction of outgrowth on poly-L-lysine but an enhancement on fibronectin and laminin. CNTF reduces the soma diameter on collagen IV but enlarges it on laminin or fibronectin. In contrast, NGF induces a reduction of both soma diameter and outgrowth, on all substrata. Plating of BCNs in the presence of anti- $\beta 1$-integrin reduces adhesion to fibronectin but does not change outgrowth. In contrast, RGD peptides block adhesion to laminin and poly-t-lysine and, additionally, reduce outgrowth on laminin. These data suggest that BCNs use different $\beta 1$-integrin-dependent as well as RGD-dependent mechanisms for adhesion and outgrowth on different ECM substrata, providing possible sites of modulation by specific GFs.

${ }^{1}$ Corresponding author.

\section{Introduction}

Growth factors (GFs) play an important role in neuronal development by promoting or modulating neuronal survival, neurite outgrowth, pathfinding, and synapse formation (for review, see LeviMontalcini 1987; Barde 1990). In addition, they also seem to be involved in structural and functional changes associated with adult neuronal plasticity (Kang and Schuman 1995; Korte et al. 1995; Patterson et al. 1996). The effect of a GF is not only specific to a particular cell type but is also determined by other factors. These include the presence and interaction with other cells, neurons, or glia, as well as the composition of the extracellular matrix (ECM). Recent data from vertebrates and invertebrates indicate that ECM molecules may activate intracellular signaling cascades and thereby modulate cellular attachment, motility, and neuronal outgrowth. The question now arises how, during these processes, ECM-induced signaling interacts with signaling pathways activated by GFs.

ECM signaling is initiated by the interaction of distinct ECM sequences with specific cellular receptors. The best described family of ECM receptors are the integrins that can interact with a number of ECM components, including laminin, fibronectin, and different collagens (de Curtis 1991; Schwartz et al. 1995). The interaction can involve different peptide sequences within the ECM molecules, among them the RGD sequence (Arg-GlyAsp) that is contained in laminin, fibronectin, and collagen IV (Yamada 1991; Ruoslahti 1996). Moreover, integrins can modulate a variety of signal transduction pathways (Schwartz et al. 1995). A common theme of integrin signaling seems to be the induction of tyrosine phosphorylation, leading to the activation of the focal adhesion kinase (FAK) and thereby to the activation of the mitogen-activated kinase (MAPK) pathway (Schaller et al. 1992;

LEARNING \& MEMORY 6:292-306 @ 1999 by Cold Spring Harbor Laboratory Press ISSN1072-0502/99 \$5.00

$$
\begin{array}{lllllllllllllll}
L & E & A & R & N & I & N & G & \underset{\mathbf{2 9 2}}{\boldsymbol{Z}} & M & E & M & O & R & Y
\end{array}
$$


Schlaepfer et al. 1994). Thus, tyrosine kinases present a potential convergence site for integrin- and GF-induced signaling, and cooperative effects of ECM and GF on tyrosine phosphorylation of different proteins have been observed (summarized by Schwartz et al. 1995). Furthermore, direct associations between integrins and activated receptors for both platelet-derived growth factor (PDGF) and insulin have been detected in fibroblasts (Schneller et al. 1997).

Proteins with homology to vertebrate ECM components also exist in invertebrates (for review, see Har-El and Tanzer 1993). For example, fibronectin-like molecules have been detected in organisms as diverse as Helisoma, Drosopbila, sea urchin, and Dictyostelium (Iwata and Nakano 1981; Springer et al. 1984; Gratecos et al. 1988; Mattson and Kater 1988). In many cases, invertebrate cells use the same RGD sequence for adhesion that is also commonly used by vertebrate cells (Mattson and Kater 1988; Bunch and Brower 1992; Ziegler and Stidwill 1992). These ECM molecules as well as their cellular receptors seem to be conserved among vertebrates and invertebrates (Bogaert et al. 1987; Marcantonio and Hynes 1988; Gettner et al. 1995; Wu et al. 1996).

Although initially discovered in vertebrates, GFs and their receptors also exist in invertebrates and fulfill similar functions as in vertebrates. For example, Lymnaea cysteine-rich neurotrophic factor (CRNF) binds specifically to the vertebrate p75 neurotrophin receptor and evokes outgrowth from Lymnaea pedal motor neurons (Fainzilber et al. 1996). Neurite outgrowth from cultured Lymnaea neurons is also induced by vertebrate nerve growth factor (NGF) and ciliary neurotrophic factor (CNTF) (Ridgway et al. 1991; Syed et al. 1996). Although no endogenous neurotrophins have been characterized in molluscs yet, effects of different vertebrate GFs on the structure and physiology of molluscan neurons have been described: the transforming growth factor TGF- $\beta$ induces long-term facilitation of the synaptic connections between Aplysia sensory and motor neurons (Zhang et al. 1997), and a similar effect was found for human BDNF (S.E. McKay and T.J. Carew unpubl.). Finally, an insulin receptor with homology to its vertebrate counterpart has been cloned in Aplysia and seems to regulate excitability and neuropeptide release of neuroendocrine bag cell neurons (BCNs; Jonas et al. 1996).

The marine mollusk Aplysia californica provides a well-characterized model system to study functional and structural changes associated with synaptic plasticity as well as their developmental emergence. Although different Aplysia neurons have been used extensively in cell culture studies over the last decades, a detailed investigation of the interaction of Aplysia neurons with different ECM molecules as well as an analysis of the endogenous Aplysia ECM has not yet been undertaken. However, a CAM-like cell adhesion molecule (ApCAM) and an integrin-like ECM receptor are expressed in Aplysia neurons and may both be involved in structural changes (Mayford et al. 1992; Wu et al. 1996). The main goal of this study was to investigate how different factors modulate structural features of outgrowing Aplysia neurons in culture. BCNs are a good model system for these studies as they are not dependent on serum or GFs for their adhesion and survival. This allowed us to study the effects of purified ECM molecules and GFs on these neurons. We started our analysis by testing the attachment of Aplysia BCNs to different vertebrate ECM molecules, and we examined the patterns of neuronal outgrowth that were induced by them. We then investigated the differential interaction with GFs of BCNs that were pregrown on different ECM substrata. Finally, we began to analyze the molecular mechanisms that are used for the adhesion and outgrowth on the different ECM substrata with the goal of identifying how these mechanisms might be modulated by specific GF actions. Preliminary results have been presented in abstract form (Gruenbaum et al., unpubl.).

\section{Materials and Methods}

Wild-caught adult Aplysia californica (100150 grams; purchased from Marinus, CA) were used for all experiments. Dispase (neutral protease) and mouse laminin were from Boehringer Mannheim Biochemica; bovine plasma fibronectin, poly-L-lysine (high molecular weight, >300,000), and mouse collagen type IV were from Sigma.

BDNF (human, recombinant) was a gift from Amgen, Inc., NGF (2.5S, mouse) was obtained from Boehringer Mannheim Biochemica, and CNTF (rat, recombinant) was from Calbiochem. The monoclonal anti- $\beta 1$-chicken integrin antibody and RGD peptide were from Sigma. GRGDSP and GRGESP (control) were from GIBCO BRL (Life Technologies). Fluorescein goat anti-rabbit IgG $(\mathrm{H}+\mathrm{L})$ conjugate was from Molecular Probes; the monoclonal rabbit anti- $\beta$-tubulin antibody, from Sigma.

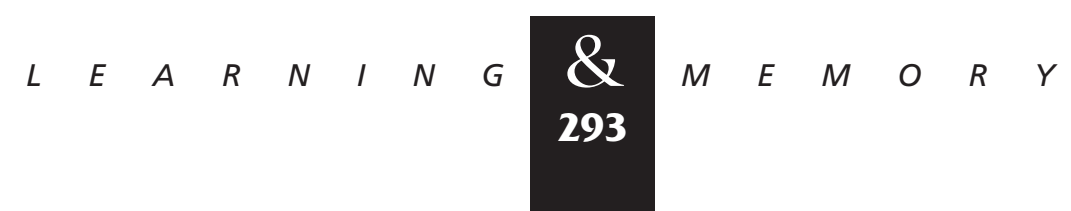




\section{Gruenbaum and Carew}

\section{SUBSTRATE PREPARATION}

Glass coverslips were soaked overnight in $8 \mathrm{~N}$ $\mathrm{HCl}$, rinsed with water, and soaked again overnight in $95 \%$ ethanol. Coverslips were stored in 95\% ethanol until use. Ethanol was removed either by flame or by room temperature evaporation, and coverslips were placed in culture dishes and covered with the substrate solution: laminin $(50 \mu \mathrm{g} /$ $\mathrm{ml})$, fibronectin $(50 \mu \mathrm{g} / \mathrm{ml})$, poly-L-lysine $(20 \mu \mathrm{g} /$ $\mathrm{ml})$, or collagen $(20 \mu \mathrm{g} / \mathrm{ml})$. After incubation for at least $30 \mathrm{~min}$, coverslips were rinsed several times with sterile water and the dishes were filled with artificial sea water (ASW: $460 \mathrm{~mm} \mathrm{NaCl}, 10.4 \mathrm{~mm}$ $\mathrm{KCl}, 55 \mathrm{~mm} \mathrm{MgCl}_{2}, 11 \mathrm{~mm} \mathrm{CaCl}, 15 \mathrm{~mm}$ HEPES, 1 $\mathrm{g} /$ liter of glucose, $100,000 \mathrm{U} /$ liter of penicillin, $100 \mathrm{mg} /$ liter of streptomycin at $\mathrm{pH}$ 7.8).

\section{NEURON ISOLATION AND CULTURE}

Dissociated BCNs were produced modifying the procedure described by Kaczmarek et al. (1979). Aplysia were anesthetized by injection of $60 \mathrm{ml}$ of $0.5 \mathrm{M} \mathrm{MgCl}_{2}$. Animals were immediately dissected, and abdominal ganglia were removed, preserving lengths of the pleural-abdominal connectives. Ganglia were incubated in 1\% dispase in ASW (460 mм NaCl, 10.4 mm KCl, 55 mm $\mathrm{MgCl}_{2}, 11$ $\mathrm{mm} \mathrm{CaCl}_{2}, 15 \mathrm{~mm}$ HEPES, 1 gram/liter glucose, 100,000 U/liter penicillin, $100 \mathrm{mg} /$ liter streptomycin at $\mathrm{pH} 7.8$ ) at room temperature for $18 \mathrm{hr}$. Ganglia were transferred to culture dishes, and $\mathrm{BCN}$ clusters were dissected from the pleural-abdominal connective, and connective tissue was removed using forceps and microscissors. Clusters were transferred to the precoated culture dishes and dissociated by gently pipetting them up and down. Ten to 20 cells were distributed on the coverslip in each culture dish at sufficient distance from each other so that an overlap of outgrowth and the formation of synapses between BCNs would not occur. Culture dishes were not moved for the first $3 \mathrm{hr}$ after preparation to allow BCNs to settle. Cultures were kept for 2 days at $15^{\circ} \mathrm{C}$ before performing immunostaining. Each culture contained BCNs cultured on uncoated coverslips as a negative control (no attachment or outgrowth) and BCNs cultured directly on plastic as a positive control (good attachment and outgrowth).

\section{BCN CULTURE TREATMENTS}

All GF treatments (BDNF, $50 \mathrm{ng} / \mathrm{ml}$; NGF, 20 $\mathrm{ng} / \mathrm{ml}$; and CNTF, $1 \mathrm{~nm}$ ) were performed after preculturing BCNs for 1 day on different substrata. GFs were added to ASW in the culture dishes, and incubation was continued for another day. In some cultures cytochrome $\mathrm{C}$ was used as a negative control, but no difference in BCN morphology was ever noticed between cytochrome $\mathrm{C}$ and untreated BCNs.

Anti- $\beta 1$-integrin (1:200) and RGD peptides (RGD, GRGDSP, or GRGESP; all $50 \mu \mathrm{m}$ ) were added to the ASW in the culture dishes immediately before plating the BCNs. Culture were kept for 2 days before performing immunostaining.

Anti- $\beta 1$-integrin (1:200) recognized two proteins of apparent molecular masses of $\sim 70$ and 150 $\mathrm{kD}$ in Western blots (performed under reducing conditions) from Aplysia nervous tissue. These weights resemble the molecular masses detected with anti- $\beta 1$-integrin in Western blots of chicken (70 and $140 \mathrm{kD}$ ), or Caenorbabditis elegans tissues (70 and $120 \mathrm{kD}$; Marcantonio and Hynes 1988). In all cases, the $70-\mathrm{kD}$ protein most probably represents a proteolytic degradation product from the full-length integrin (Marcantonio and Hynes 1988).

To minimize variability between animals, controls (without treatment) and treatments were always performed for BCNs cultured from the same ganglion.

\section{IMMUNOCYTOCHEMISTRY}

All steps were performed at room temperature. To save antibody solution and to allow for a rapid change of solution, "sandwiches" were created by fixing two small plastic spacers with grease on the coverslips to which the BCNs were attached. A chamber containing the BCNs was then created by fixing another (unused) coverslip to the spacers on top of the first one. BCNs were fixed for 30 min with cold fixative (1\% glutaraldehyde, $4 \%$ formaldehyde, $400 \mathrm{~mm}$ sucrose, ASW pH 7.6). Cells were permeabilized with $1 \%$ Triton X-100 in fixative for $5 \mathrm{~min}$ and afterwards washed twice with PBS-Triton (0.1\% Triton X-100, PBS pH 7.4). Nonspecific attachment of antibodies to $\mathrm{BCNs}$ was prevented by blocking with 5\% BSA in PBS for $15 \mathrm{~min}$. Coverslips were quickly rinsed and incubated with anti- $\beta$-tubulin for $30 \mathrm{~min}$. After washing with PBSTriton, coverslips were covered with fluorescein goat anti-rabbit IgG for $15 \mathrm{~min}$, rinsed again, and mounted on slides with Citifluor.

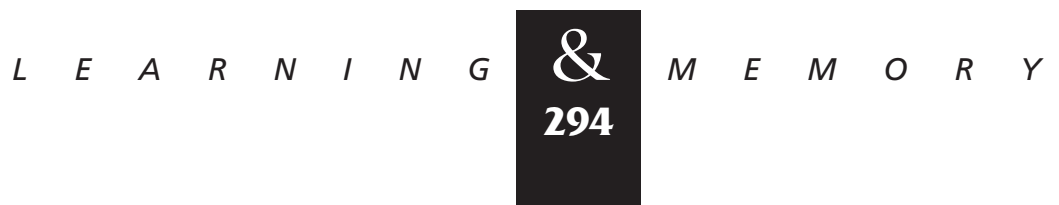




\section{ADHESION}

The number of BCNs on each coverslip was determined immediately after plating, and the number of BCNs that were attached to the substrate was determined 1 and 2 days later. Unattached BCNs do not survive under these culture conditions and float to the surface of the culture medium. In some cases, cells did not float to the surface but showed clear signs of cell death in their morphology. These cells were apparently not functionally attached to the substratum as they were removed from it during the immunostaining procedure and were thus also counted as unattached. The adhesion rate was calculated by dividing the number of attached cells on day 3 by the number of initially plated cells.

\section{MORPHOLOGICAL MEASUREMENTS}

Pictures of stained BCNs were taken with a confocal laser scanning microscope (krypton/argon laser). Different parameters of cellular morphology were determined from these laser scans using NIH Image. These included the soma diameter and the total cytosolic area (excluding the nucleus), the total branch length of neurites per cell, the number of neurites, and number of branchpoints per cell.

\section{STATISTICAL ANALYSIS}

All data were normally distributed. Comparisons between BCNs on the four different substrata were done using an ANOVA and a post hoc $t$-test. Comparisons between controls and treated BCNs were performed using Student's unpaired $t$-test. $N \mathrm{~s}$ represent the number of coverslips in the experiments for the determination of adhesion rates, whereas they represent the total number of measured cells on all coverslips for the analysis of BCN morphology. Mean values for which at least $P<0.05$ (two tailed) were regarded as significantly different from each other.

\section{Results}

BCN MORPHOLOGY AND NEURITE OUTGROWTH IS SUBSTRATE DEPENDENT

To analyze the potential role of different substrates in BCN morphology and outgrowth, we plated BCNs on glass coverslips that had been coated with isolated components of vertebrate ECM (laminin, fibronectin, or collagen). Glass coverslips were chosen as they do not support attachment or outgrowth by themselves. Positive controls for each culture included BCNs cultured on plastic or on poly-L-lysine that both support strong adhesion and outgrowth. After 2 days in culture, BCNs were visualized by tubulin immunostaining followed by confocal microscopy (see Materials and Methods). BCNs adhere to all chosen substrata to a comparable level. Although adhesion rates were quite variable among cultures from different ganglia (60\%-90\%), no significant differences were found between different substrata for cultures from the same ganglion $[F(3,34)=0.27, \quad P=$ 0.8448 for all comparisons]. Interestingly, BCNs have a very distinct morphology depending on the choice of substrate (Fig. 1): Whereas BCNs on laminin and fibronectin show relatively little outgrowth, outgrowth is much more extensive on poly-L-lysine and collagen. Neurites of BCNs grown on laminin or fibronectin are thicker, and the num-

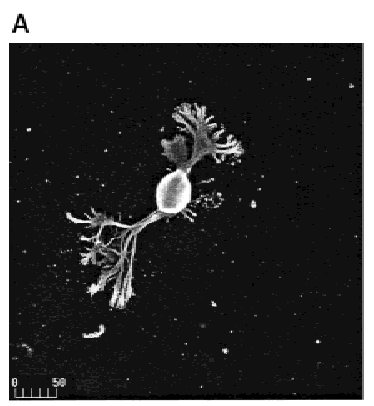

laminin

C

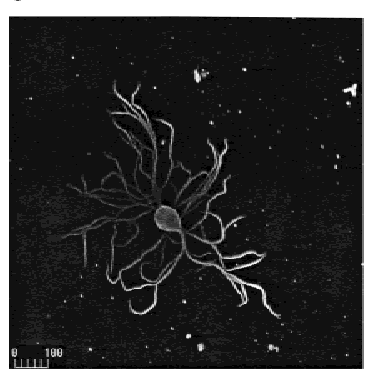

poly-L-lysine

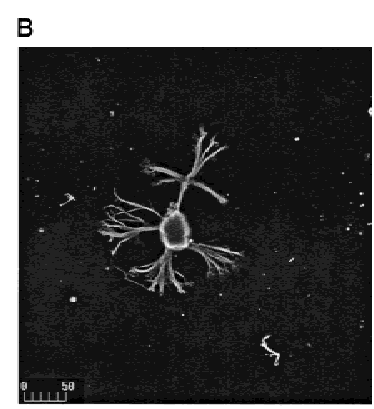

fibronect in

D

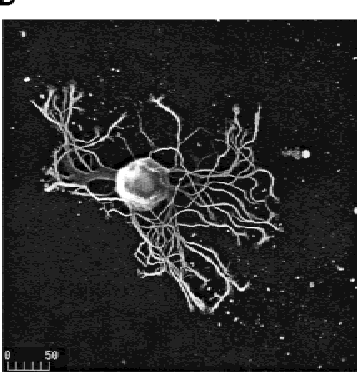

Figure 1: $\quad B C N$ s adhere to different substrata and show substrate-dependent morphology. BCNS were plated on glass coverslips precoated with laminin $(A)$, fibronectin $(B)$, poly-L-lysine $(C)$, or collagen $(D)$. Immunostaining with anti- $\beta$-tubulin was performed after 2 days of culture and was visualized using a fluorescein-coupled secondary antibody. Photomicrographs were taken with a confocal laser scanning microscope. Scale bar, $\mu \mathrm{m}$.

$$
\begin{array}{llllllllllllllll}
\hline & E & A & R & N & I & N & G & \mathbf{Z} & M & E & M & O & R & Y
\end{array}
$$




\section{Gruenbaum and Carew}

ber of primary neurites, total neurites, and branchpoints are lower on these substrata than on polyL-lysine or collagen.

To quantify substrate-dependent differences in BCN morphology, several parameters were measured: These included the apparent soma diameter and total cytosolic area of BCNs (excluding the nucleus), as well as the total branch length of neurites and the number of branches and of branchpoints per BCN. The latter three parameters changed in very similar patterns in all experiments performed. However, modulation of these parameters was very distinct from the modulation of the soma diameter; therefore, changes in soma diameter and total branch length (as representative for neurite outgrowth) are compared separately. Statistical analysis of these parameters confirmed the aforementioned observations: Neurite outgrowth (measured by total branch length per BCN) is significantly less exuberant on laminin and fibronectin than on poly-L-lysine or collagen [Fig. 2; $F(3,401)=4.8, P=0.0026]$. Interestingly, the apparent soma diameter of BCNs grown on poly-Llysine or collagen is also significantly larger than on laminin or fibronectin $[F(3,317)=23.6, P<0.0001]$. No significant differences were detected for both parameters between poly-L-lysine and collagen or between laminin and fibronectin. These data thus show that typical components of vertebrate ECM support neuronal adhesion and outgrowth in Aplysia as well. In addition, different substrates induce a distinct morphology of BCNs.

\section{THE INTERACTION OF BCNS WITH GFs IS SUBSTRATE DEPENDENT}

Having shown that BCN morphology in culture is substrate dependent, we then asked whether the interaction of BCNs with GFs might also be modulated by the choice of substrate. In these experiments it was not possible to perform all the control and GF treatments on BCNs cultured from the same ganglion. Because the focus of this series of experiments was on the differences between control and GF treatment for each substrate, these comparisons were always made on neurons taken from the same ganglion. Because of the fact that controls were of necessity taken from different ganglia, there is more intrinsic variability among controls compared with experiments in which substrate effects were directly explored (see Fig. 2). Nonetheless, in the vast majority of cases, the controls exhibited growth patterns in the direction
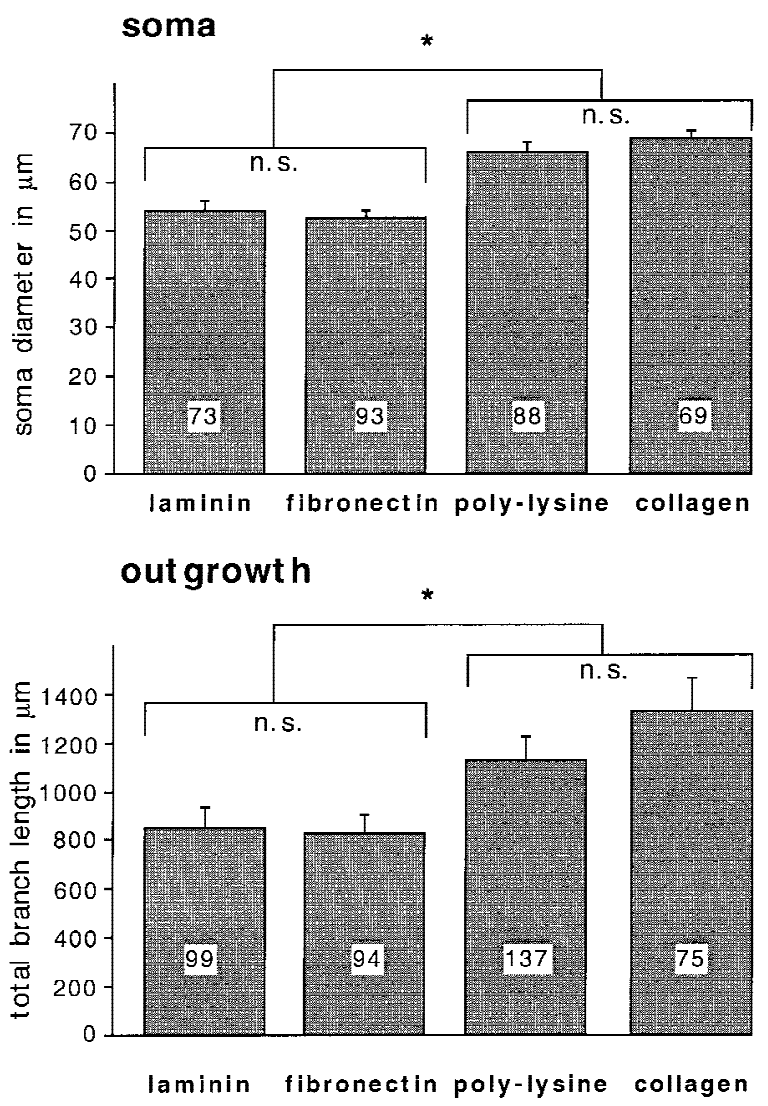

Figure 2: Soma diameter and neurite outgrowth of $\mathrm{BCN}$ s are modulated in a substrate-dependent fashion. $\mathrm{BCN}$ s were cultured on different substrata and stained as described for Fig. 1. Morphological measurements were performed on laser microscope scans (as shown in Fig. 1) using NIH Image. The soma diameter (soma) and the total branch length of neurites (outgrowth) were measured for each cell. Here and in Figs. 3-9, numbers in the histograms indicate the number of cells examined in each condition. Asterisks $(*)$ indicate means that are significantly different from each other $(P<0.05)$.

predicted from the first series of experiments (Fig. 2).

S.E. McKay and T.J. Carew (unpubl.) have shown that human, recombinant BDNF can induce long-term facilitation at the tail sensory-motor synapses in Aplysia. Therefore, we first chose to study the effects of this factor on BCN outgrowth in culture. BCNs were precultured for 1 day on the different substrata before BDNF was added, and cultures were kept for another day in BDNF. Cellular morphology was visualized as before by immunostaining and confocal microscopy.

As shown in Figure 3, BDNF $(50 \mathrm{ng} / \mathrm{ml})$ induced no change in the soma diameter on any substrate. However, it did induce substrate-specific

$$
\begin{array}{lllllllllllllllllllll}
\mathbf{2} & E & A & R & N & I & N & G & \mathbf{Q} & M & E & M & O & R & Y
\end{array}
$$




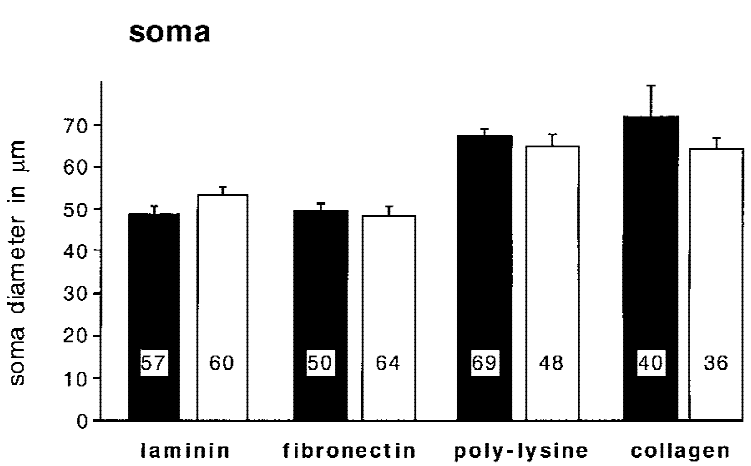

out growt $h$

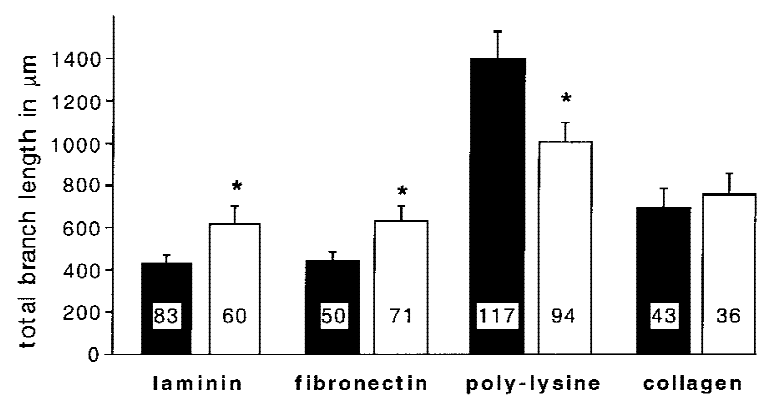

Figure 3: BDNF differentially modulates soma diameter and neurite ougrowth of BCNs in a substrate-dependent fashion. BCNs were grown on different substrata for 1 day and incubated with BDNF $(50 \mathrm{ng} / \mathrm{ml})$ for another day before immunostaining. Soma diameter and total branch length of neurites were measured for each cell as described for Fig. 2. Statistical comparisons were performed for untreated cells (solid bars) and BDNF-treated cells (open bars) that were grown on the same substrate.

changes of neurite outgrowth: Outgrowth is significantly enhanced on laminin $(P=0.022)$ and fibronectin $(P=0.043)$ but significantly reduced on poly-L-lysine $(P=0.026)$. It is not changed on collagen.

In similar experiments we also investigated the effects of two other GFs, NGF and CNTF, on BCN morphology. Both factors had been shown to stimulate neurite outgrowth in Lymnaea cell culture (Ridgway et al. 1991; Syed et al. 1996). We found that these factors affect BCN morphology in different ways than BDNF. As shown in Figure 4, NGF $(20 \mathrm{ng} / \mathrm{ml})$ induces a significant reduction of both soma diameter and neurite outgrowth that is independent of the choice of substrate $(P<0.02$ for all comparisons). In contrast, CNTF ( $1 \mathrm{nM})$ does not change neurite outgrowth on any of the substrata (Fig. 5). However, it modulates the soma diameter in a substrate-specific manner: Whereas the soma diameter is significantly enhanced on laminin
$(P=0.005)$ and fibronectin $(P=0.0001)$ after CNTF treatment, it remains unchanged on poly-Llysine and is significantly reduced in the case of collagen $(P=0.030)$.

Table 1 summarizes the effects of the three GFs on soma diameter and neurite outgrowth. Interestingly, the effect of BDNF on neurite outgrowth and the effect of CNTF on soma diameter seem to counteract the effects that the substrata alone exert on these morphological parameters (shown schematically in Fig. 10, below). In the case of laminin and fibronectin, which do not induce extensive outgrowth by themselves, BDNF stimulates outgrowth. In contrast, in the case of poly-L-lysine, which by itself induces exuberant outgrowth, BDNF inhibits growth. In addition, the small soma diameter of BCNs on laminin and fibronectin are enlarged after CNTF treatment, whereas the large soma diameter on collagen are reduced

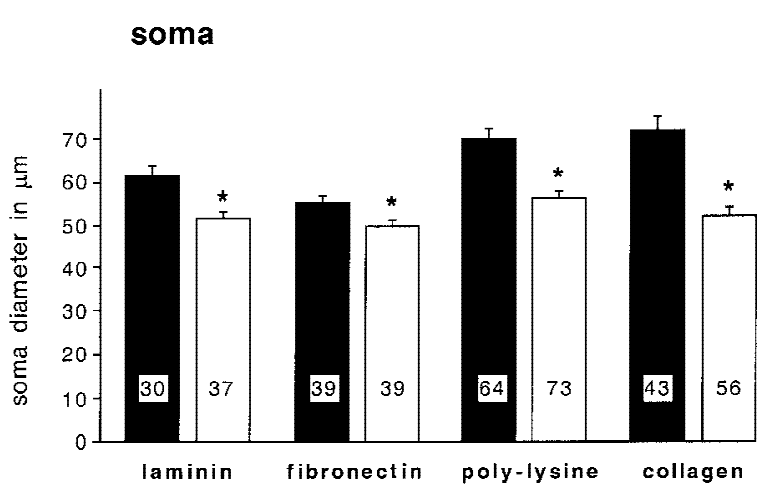

out growt h

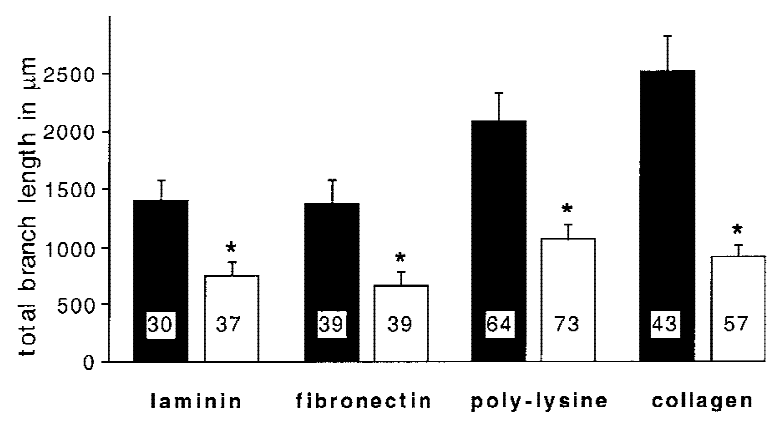

Figure 4: NGF leads to a reduction of soma diameter and neurite outgrowth of BCNs on all substrata. BCNs were grown on different substrata for 1 day and incubated with NGF (20 ng/ml) for another day before immunostaining. Statistical comparisons were performed for untreated cells (solid bars) and NGF-treated cells (open bars) that were grown on the same substrate. In all cases means for NGF-treated cells are significantly lower than the corresponding controls $(P<0.05)$.

$$
\begin{array}{llllllllllllllll}
\mathbf{Q} & E & A & R & N & I & N & G & \underset{297}{\mathbf{Z}} & M & E & M & O & R & Y
\end{array}
$$



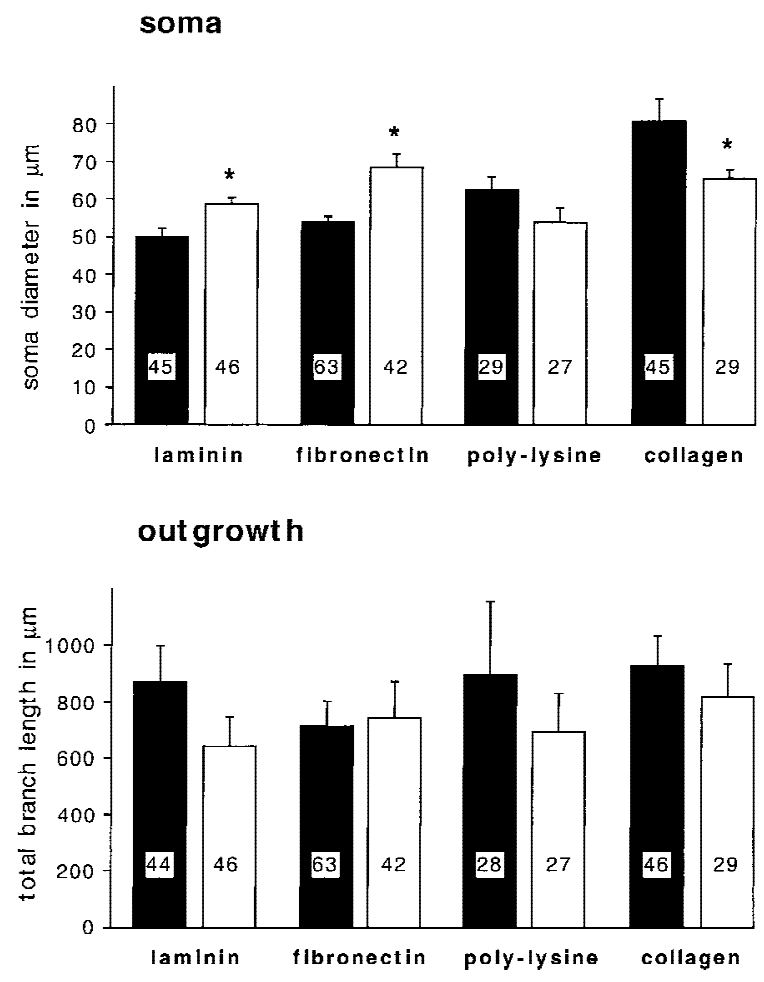

Figure 5: CNTF modulates soma diameter in a substrate-dependent fashion but does not change neurite outgrowth. BCNs were grown on different substrata for 1 day and incubated with CNTF (1 nм) for another day before immunostaining. Statistical comparisons were performed for untreated cells (solid bars) and CNTFtreated cells (open bars) that were grown on the same substrate.

by CNTF. None of the GFs affect adhesion rates of BCNs to the different substrata (data not shown). In summary, each GF has its own signature: BDNF differentially modulates branch length (but not soma diameter), CNTF differentially modulates soma diameter (but not branch length), and NGF modulates both morphological features, but not differentially.

DIFFERENT MOLECULAR MECHANISMS CONTRIBUTE TO ADHESION AND TO OUTGROWTH

ON DIFFERENT SUBSTRATA

Understanding how specific GFs exert unique effects on neuronal growth patterns will require identifying the molecular mechanisms that might contribute to the substrate-specific adhesion and outgrowth of BCNs that we observe. The differential interactions of BCNs with different substrata and GFs described above suggest that distinct mechanisms may be involved in adhesion and/or outgrowth on the different substrata (see Table 1). Likely candidates that have been shown to mediate adhesion of a variety of vertebrate cells in vivo and in vitro are the integrins. Therefore, we analyzed the effects of anti- $\beta 1$-integrin on $\mathrm{BCN}$ adhesion and outgrowth on different substrata.

We found that anti- $\beta 1$-integrin $(1: 200)$ specifically reduces adhesion of BCNs to fibronectin by 56\% $(P=0.03)$, whereas it does not significantly affect adhesion to the other substrata (Fig. 6). Additionally, it modulates the soma diameter but not the neurite outgrowth of BCNs (Fig. 7): In a pattern, reminiscent of the effects of CNTF (Fig. 5), anti- $\beta 1$-integrin promotes a significant enlargement of soma diameter on laminin $(P=0.007)$ and fibronectin $(P=0.005)$, no change on poly-L-lysine, and a significant reduction on collagen $(P=0.017)$.

In contrast to anti- $\beta 1$-integrin, the RGD peptides RGD and GRGDSP significantly reduced the adhesion rate on laminin by $44 \%(P=0.02)$ and on poly-L-lysine by $50 \%(P=0.045)$ but did not significantly alter the adhesion to fibronectin or collagen (Fig. 8). The effects of RGD and GRGDSP were in no case significantly different from each other (data not shown). These data suggest that adhesion to laminin involves a mechanism that is $\beta 1$-integrin independent but is RGD dependent, whereas adhesion to fibronectin requires a process that is $\beta 1$ integrin dependent but is RGD independent. Finally, as shown in Figure 9, we found that RGD peptides modulate neurite outgrowth but not soma diameter. Outgrowth is selectively reduced only on laminin $(P=0.046)$. These findings suggest that an RGD-dependent mechanism contributes to both adhesion and outgrowth on laminin (Figs. 8 and 9), whereas different mechanisms seem to be involved in adhesion and outgrowth on fibronectin (see Fig. 11, below).

\section{Discussion}

\section{DIFFERENT VERTEBRATE ECM MOLECULES}

SUPPORT BCN ADHESION AND INDUCE

SUBSTRATE-SPECIFIC PATTERNS OF NEURITE OUTGROWTH

In this study we have shown that neuroendocrine BCNs from Aplysia adhere readily to the vertebrate ECM molecules laminin, fibronectin, and collagen IV. In addition, all these ECM molecules induce neurite outgrowth from BCNs. Moreover, neurite outgrowth is regulated in a substrate-spe-

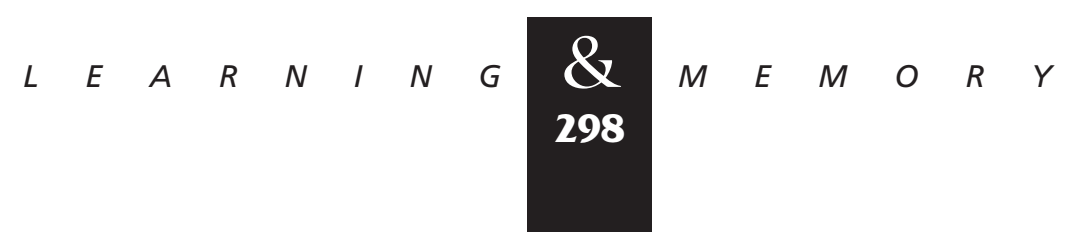


Table 1: Differential effects of neurotrophins (BDNF, NGF, CNTF) on soma diameter and branch length of $B C N$ s that were grown on different substrata

\begin{tabular}{|c|c|c|c|c|c|c|}
\hline & \multicolumn{2}{|c|}{ BDNF } & \multicolumn{2}{|c|}{ NGF } & \multicolumn{2}{|c|}{ CNTF } \\
\hline & $\begin{array}{c}\text { soma } \\
\text { diameter }\end{array}$ & $\begin{array}{l}\text { branch } \\
\text { length }\end{array}$ & $\begin{array}{c}\text { soma } \\
\text { diameter }\end{array}$ & $\begin{array}{l}\text { branch } \\
\text { length }\end{array}$ & $\begin{array}{c}\text { soma } \\
\text { diameter }\end{array}$ & $\begin{array}{l}\text { branch } \\
\text { length }\end{array}$ \\
\hline Laminin & $\leftrightarrow$ & $\uparrow$ & $\downarrow$ & $\downarrow$ & $\uparrow$ & $\leftrightarrow$ \\
\hline Fibronectin & $\leftrightarrow$ & $\uparrow$ & $\downarrow$ & $\downarrow$ & $\uparrow$ & $\leftrightarrow$ \\
\hline Poly-L-lysine & $\leftrightarrow$ & $\downarrow$ & $\downarrow$ & $\downarrow$ & $\leftrightarrow$ & $\leftrightarrow$ \\
\hline Collagen & $\leftrightarrow$ & $\leftrightarrow$ & $\downarrow$ & $\downarrow$ & $\downarrow$ & $\leftrightarrow$ \\
\hline
\end{tabular}

cific manner: Whereas laminin and fibronectin induce relatively little outgrowth and branching of neurites, poly---lysine and collagen lead to exuberant outgrowth from multiple, thin neurites and extensive branching. Interestingly, the morphology of BCNs on the latter substrata resembles the branching patterns of BCNs that are observed in vivo: $\mathrm{BCNs}$ in the abdominal ganglion are typically multipolar and show extensive branching in the surrounding connective tissue (Kaczmarek et al. 1979). One possible explanation for the different patterns of outgrowth on the different substrata we observe is that different substrata induce differ-

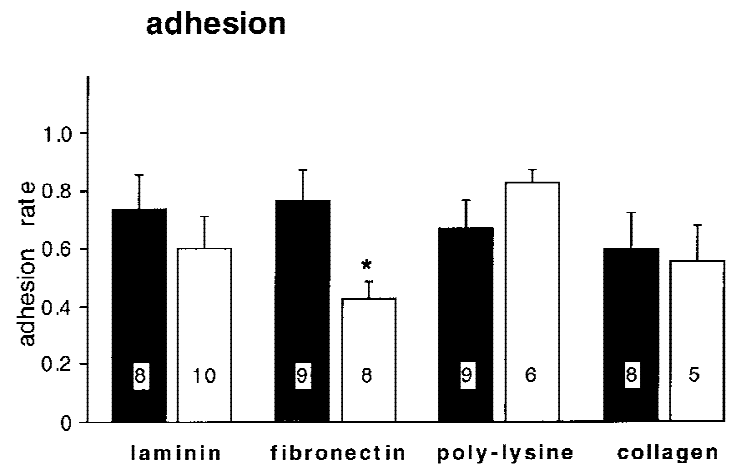

Figure 6: Anti- $\beta 1$-integrin blocks adhesion to fibronectin but not to the other substrates. Anti- $\beta 1$ integrin (1: 200) was added to ASW in the culture dishes immediately before the plating of $\mathrm{BCNs}$, which were then grown in the absence (control) or presence of anti- $\beta 1$-integrin for 2 days. The number of BCNs on each coverslip was counted immediately after plating, and the number of BCNs attached to the substrate was determined 1 and 2 days after plating. The adhesion rate was calculated by dividing the number of attached cells on day 3 by the number of initially plated cells on day 1 . Statistical comparisons were performed for untreated (solid bars) and anti- $\beta 1$-integrin-treated (open bars) coverslips that were coated with the same substrate. ent rates of outgrowth from the BCNs. In all of our experiments, BCNs were cultured for 2 days before immunostaining. Although a possible contributing factor, differential growth rate alone cannot ac-

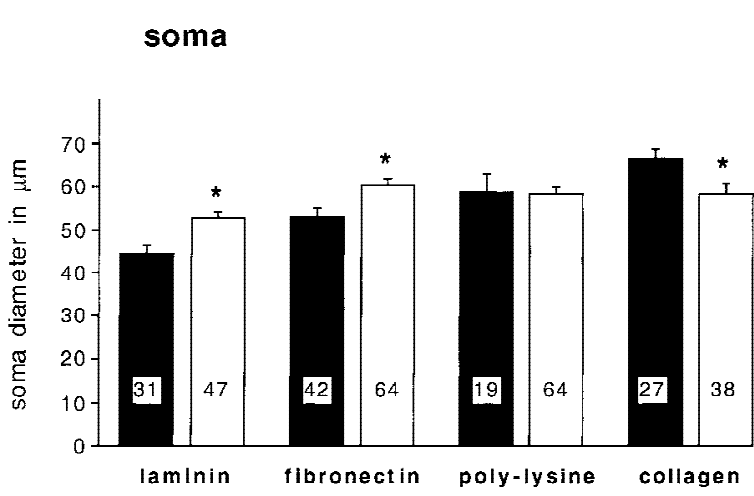

out growt h

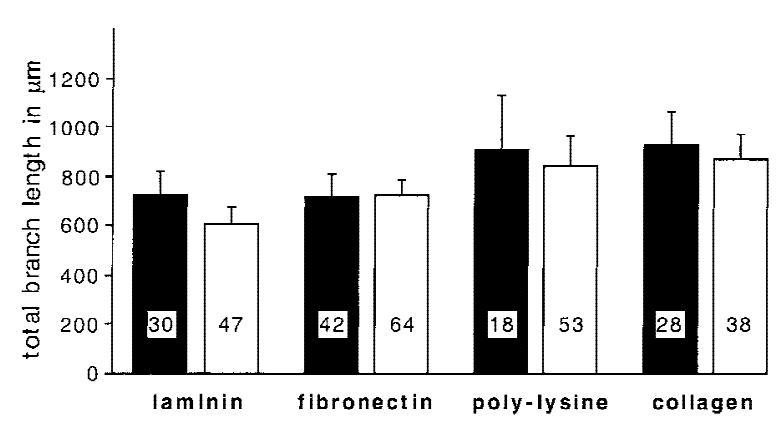

Figure 7: Anti- $\beta 1$-integrin does not interfere with neurite outgrowth but modulates the soma diameter of BCN in a substrate-specific manner. Anti- $\beta 1$-integrin (1:200) was added to ASW in the culture dishes immediately before the plating of BCNs. BCNs were grown in the absence (control) or presence of anti- $\beta 1$-integrin for 2 days before immunostaining. Statistical comparisons were performed for untreated cells (solid bars) and anti$\beta 1$-integrin-treated cells (open bars) that were grown on the same substrate. No significant changes in neurite outgrowth were detected.

$$
\begin{array}{lllllllllllllll}
L & E & A & R & N & I & N & G & \underset{2}{\mathbf{2} 99} & M & E & M & O & R & Y
\end{array}
$$




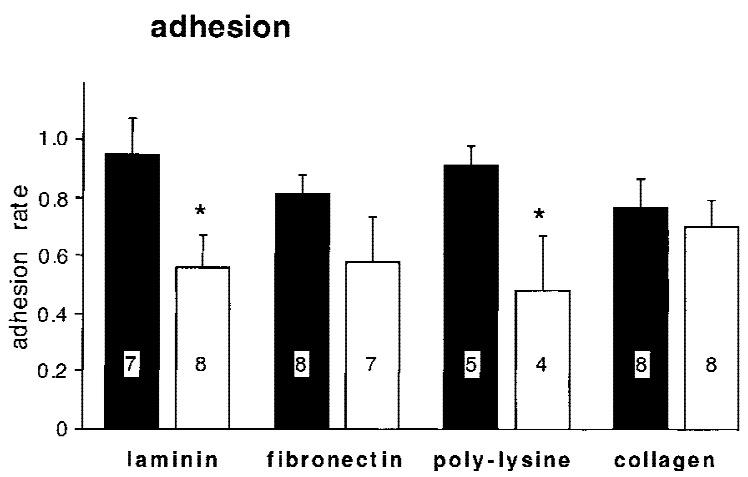

Figure 8: RGD peptides selectively reduce adhesion to laminin and poly-lysine. RGD peptides (RGD or GRGDS, both $50 \mu \mathrm{m}$ ) were added to ASW in the culture dishes immediately before the plating of BCNs. Controls were incubated in the presence of the inactive peptide GRGESP or in the absence of any peptide. The adhesion rates were determined as described for Fig. 7. No significant differences were found between BCNs treated with RGD and GRGDSP; thus, these groups were pooled in this figure (open bars). Also, adhesion of BCNs cultured in the presence of GRGESP or in the absence of any peptide was not significantly different, and these two groups were therefore pooled as controls (solid bars).

count for all of our results. For example, BCNs grown on laminin or fibronectin never reached the same degree of outgrowth as BCNs plated on polyL-lysine and collagen, even when kept in culture for a considerably longer time period (up to a week; data not shown). In addition, differences in morphology (e.g., the thickness of primary neurites) were still evident in long-term cultures, suggesting that unique substrates induce specific morphological patterns.

One of the morphological changes we observed was the differential modulation of soma diameter by specific substrates. Several factors could contribute to the differences in apparent soma diameter that we detect for BCNs cultured on different substrata. For example, an increase in soma diameter may reflect a flattening of the BCNs on the substrate and a stronger adhesion to it. But this simple explanation cannot account for all the changes in soma diameter we observe. For example, the adhesion of BCNs to fibronectin is decreased by the $\beta 1$-integrin antibody. Nevertheless, the soma diameter of BCNs plated on fibronectin is increased in the presence of this antibody. Similarly, adhesion to laminin and poly-L-lysine is reduced by RGD peptides, but the soma diameter of BCNs grown on these substrata remains un- changed compared with controls. These findings suggest that soma diameter is a morphological parameter that is regulated in our experiments, at least in part, independently of adhesion and neurite outgrowth. The fact that the soma diameter is modified by ECM molecules and growth factors raises the important question for further research as to the functional significance of the alteration of this morphological feature.

Cell cultures of BCNs and other Aplysia neurons have been used extensively for the analysis of synaptic plasticity and ion channel physiology, but all studies to date have used neurons grown on the artificial substrate poly-L-lysine. To our knowledge, this is the first study to investigate systematically the adherence and growth promoting properties of physiological ECM components in Aplysia. Although as yet no endogenous ECM molecules have
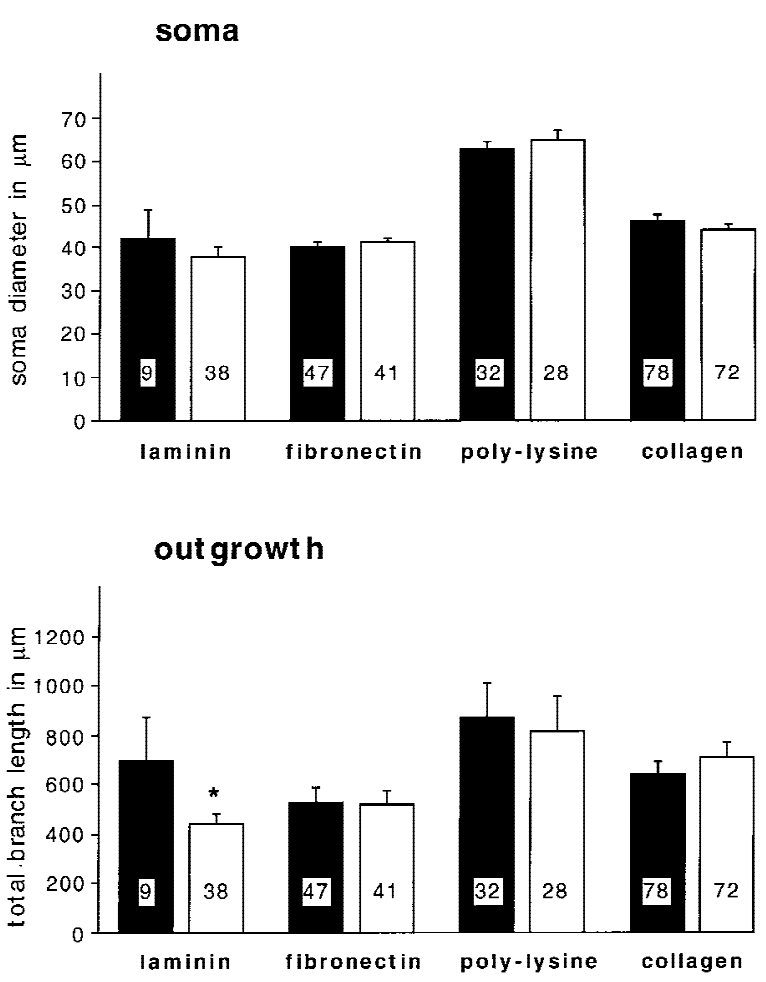

Figure 9: RGD peptides selectively inhibit neurite outgrowth on laminin. RGD peptides (RGD or GRGDS, both $50 \mu \mathrm{M}$ ) were added to ASW in the culture dishes immediately before the plating of $\mathrm{BCNs}$. Controls were incubated in the presence of the inactive peptide GRGESP or in the absence of any peptide. Immunostaining was performed after 2 days. Soma diameter and total branch length of neurites were measured for each cell as described for Fig. 2. (Solid bars) Control; (open bars) RGD. No significant changes in soma diameter were detected.

$$
\begin{array}{lllllllllllllll}
\hline & E & A & R & N & I & N & G & \mathbf{Z}_{300} & M & E & M & O & R & Y
\end{array}
$$


been characterized in Aplysia, there is good evidence in other invertebrates that ECM molecules are well conserved in phylogeny: Laminin-like molecules have been detected in Hydra, leech, Drosophila, and sea urchin (McCarthy et al. 1987; Masuda-Nakawaga et al. 1988; Fessler and Fessler 1989; Sarras et al. 1991). Molecules with similarity to fibronectin exist in Helisoma, Drosophila, sea urchin, and Dictyostelium (Iwata and Nakano 1981; Springer et al. 1984; Gratecos et al. 1988; Mattson and Kater 1988), and collagen-like molecules have been found for example in nematodes, sea urchins, and Hydra (Shimizu et al. 1990; Sarras et al. 1991; Cox 1992). These findings make it very likely that similar molecules also exist in Aplysia ECM and specifically modulate patterns of neurite outgrowth during development.

Substrate-specific differences in adherence and induction of neurite outgrowth have also been described in different vertebrate systems. Whereas chick peripheral neurons extend neurites on laminin and fibronectin, central neurons show outgrowth only on laminin (Rogers et al. 1983). Similarly, the neuronal cell line PC12 adheres readily to laminin and collagen IV but only poorly to fibronectin (Tomaselli et al. 1987). A substrate specificity in adhesion and induction of outgrowth was also found for motor neurons from the mollusk Lymnaea: These neurons attach very efficiently to laminin and collagen IV but to a significantly lower level to fibronectin (Wildering et al. 1998). In the same study neurite outgrowth induced by laminin and fibronectin was very different from each other, and no outgrowth was observed from the motor neurons plated on collagen (Wildering et al. 1998). In contrast, in the present study we found that all three substrata induce outgrowth from BCNs, indicating that the ECM encountered by these cells in vivo may contain molecules that resemble the vertebrate molecules. Although laminin and fibronectin by themselves do not induce the extensive outgrowth that is typically seen in vivo, they may in combination with GFs that increase outgrowth on these substrata (e.g., a BDNF-like molecule) lead to patterns of extensive outgrowth, too.

BCNS INTERACT IN A SUBSTRATE-DEPENDENT WAY WITH DIFFERENT VERTEBRATE GFS

Our data show that different vertebrate GFs induce unique structural changes of BCNs in culture. The different effects of the three neurotrophic GFs, BDNF, NGF, and CNTF, suggest that the effect of each single GF is specific and that Aplysia $\mathrm{BCNs}$ might also interact in vivo with more than one Aplysia GF. This hypothesis is supported by the finding that Aplysia hemolymph, which promotes strong outgrowth and increases neurite branching from Aplysia neurons, contains at least two different factors: a survival factor that is heat stable and one or more labile factors that promote outgrowth (Schacher and Prohansky 1983). Similarly, evidence in the mollusk Lymnaea suggests that different GFs exist that induce sprouting from different classes of neurons: an NGF-related molecule that affects interneurons and motor neurons and a factor that is secreted by the endocrine dorsal body cells that induces sprouting of neuroendocrine cells (Bulloch et al. 1994). Interestingly, GFs can have growth stimulatory as well as inhibitory effects on Aplysia BCNs. Inhibitory effects seem to occur predominantly in situations in which basic outgrowth is strong (see e.g., BDNF/ poly-L-lysine in Fig. 3 and NGF in Fig. 4). There is some variability in the basal outgrowth rate between different sets of experiments, and we cannot exclude the possibility that the effect of GFs on $\mathrm{BCN}$ outgrowth is additionally dependent on this rate. On the other hand, we show that a reduction of outgrowth can be induced when outgrowth is low (induced by RGD peptides for BCNs grown on laminin; see Fig. 9) as well as when outgrowth is relatively high (induced by NGF; see Fig. 4). Thus, the specific substrate and the basal growth rate may both contribute to the outcome of the GF action.

Structural effects of vertebrate GFs have been described in different invertebrate systems (Ridgway et al. 1991; Hayashi et al. 1992; Syed et al. 1996), and there is some direct evidence for the existence of endogenous invertebrate GFs and GF receptors (Pulido et al. 1992; Fainzilber et al. 1996; Jonas et al. 1996). Physiological effects of transforming growth factor TGF- $\beta$ and insulin have been demonstrated in Aplysia (Jonas et al. 1996; Zhang et al. 1997), but no structural effects induced by these molecules have been described in Aplysia as yet. Finally, the concentrations of GFs used in this study are similar to concentrations of vertebrate GFs reported to be effective in $\mathrm{Lym}$ naea cell cultures (Ridgway et al. 1991; Syed et al. 1996).

Interestingly, two different parameters of $\mathrm{BCN}$ morphology seem to be regulated independently by different GFs: Whereas BDNF modulates neurite outgrowth but does not change the apparent soma

$$
\begin{array}{lllllllllllllll}
L & E & A & R & N & I & N & G & \underset{301}{\mathbf{Z}} & M & E & M & O & R & Y
\end{array}
$$




\section{Gruenbaum and Carew}

diameter of BCNs, CNTF induces changes in soma diameter but not in neurite outgrowth. Finally, NGF leads to a reduction of both neurite outgrowth and soma diameter on all substrata. These different effects suggest the involvement of different GF receptors (corresponding possibly to members of the trk family of neurotrophin receptors and the p75 receptor) in the interaction of $\mathrm{BCNs}$ with GF. It has been shown in vertebrates that the effect of NGF, either cell survival or cell death, may depend on the combination of receptors expressed by an individual cell (for review, see Carter and Lewin 1997; Davies 1997). Although CNTF interacts with a non-trk receptor that binds to the Jak/Tyk family of tyrosine kinases, it activates some signaling pathways that are shared by trk receptors (Stahl and Yancopoulos 1994). This convergence of signaling may account for common or synergistic effects of CNTF and neurotrophins from the NGF family (Korsching 1993).

In contrast to our findings, NGF as well as CNTF stimulate outgrowth from Lymnaea neurons in culture (plated on poly-L-lysine; Ridgway et al. 1991; Syed et al. 1996). However, in these studies only motor neurons and interneurons showed outgrowth in response to CNTF; neurosecretory cells were unresponsive. In contrast, neurons from all three classes were responsive to NGF. Thus, the response of invertebrate (as of vertebrate) neurons to a particular GF seems to be cell type-specific, and this specificity may vary between species. This notion is further supported by the finding that neurons from Helisoma, a mollusk that is closely related to Lymnaea, do not show sprouting in response to NGF (Bulloch et al. 1994).
Another difference between the Lymnaea and our culture system is the use of medium for the culture: Whereas Leibovitz-15 medium was used for Lymnaea cultures, we kept the Aplysia BCNs in artificial seawater in the absence of any medium. This difference may at least partly account for the differences observed in responses of Aplysia and Lymnaea neurons to vertebrate GFs.

The specific response of BCNs to a particular GF is additionally determined by the ECM substrate. Interestingly, the response to BDNF and CNTF seems to depend on the "presetting" of BCN morphology by the ECM substrata alone. For example, as illustrated in Figure 10, in the case of CNTF, the small soma diameter of BCNs on laminin or fibronectin is enlarged by this GF, whereas the large soma diameter on collagen is reduced. In the case of BDNF, BCNs that are precultured on laminin or fibronectin, which both induce only sparse outgrowth by themselves, show significantly enhanced outgrowth. In contrast, BCNs that grow out extensively on poly-L-lysine are inhibited in their outgrowth in the presence of BDNF. These data suggest that during the first day of culture (in the presence of the substrata alone) the ECM molecules preset signaling cascades that subsequently determine the outcome of the interaction with the GFs. The interaction with the GFs then leads to a more similar morphology of BCNs grown on the different substrata; Thus, the GFs counteract the effects of ECM components on BCN morphology.

These findings indicate that ECM molecules activate different signaling cascades in BCNs and that there must be some crosstalk between these signaling processes and those that are activated by

Figure 10: Schematic drawing illustrating how the effects of GFs on soma diameter or neurite outgrowth may be determined by the presetting of these morphological features by the substrate itself. Two examples are depicted that illustrate one hypothesis (see text for details): (Left) $\mathrm{BCN}$ grown on collagen have a significantly larger soma diameter than BCNs grown on laminin or fibronectin. CNTF now leads to an enlargement of the small soma diameter of BCNs on laminin or fi-

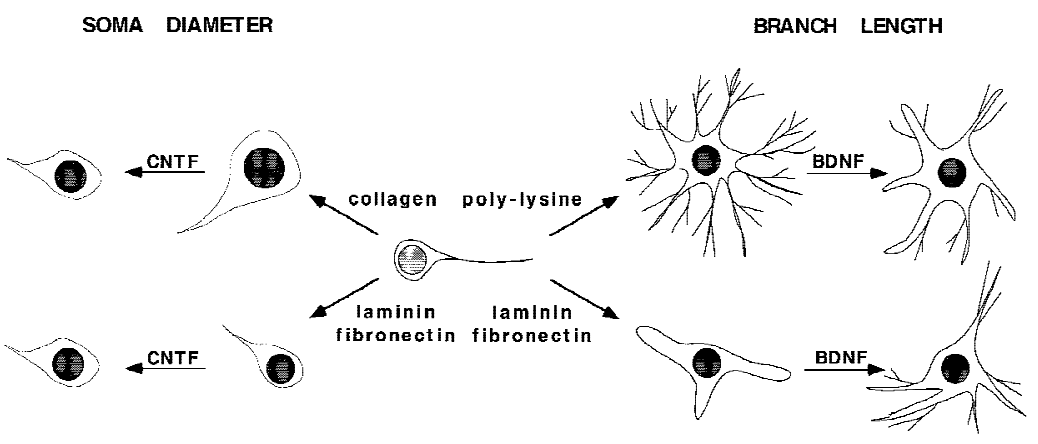
bronectin, whereas it induces a reduction of the soma diameter of BCNs on collagen. (Right) Laminin and fibronectin induce only relatively little neurite outgrowth compared with poly-L-lysine. However, outgrowth on laminin and fibronectin is increased significantly in the presence of BDNF, whereas BDNF leads to an inhibition of outgrowth on poly-Lysine. These findings suggest that there is crosstalk between substrate-induced and GF-induced intracellular signaling pathways: The substrate causes a presetting of intracellular signaling cascades and thereby modulates the signaling process activated by GFs.

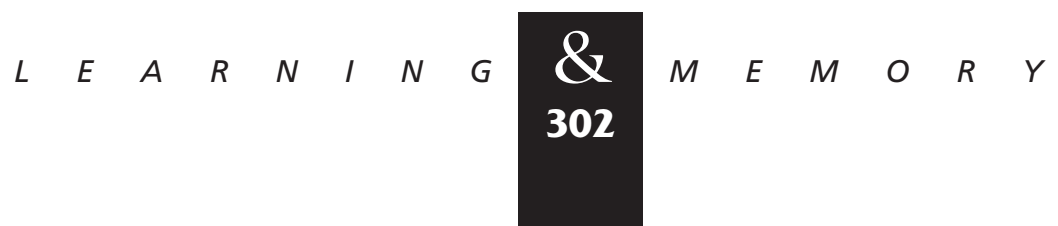


GFs. Different signaling mechanisms have been described for laminin, fibronectin, and collagen involving receptors of the integrin type as well as tyrosine kinase receptors (Schwartz 1995; Shrivastava et al. 1997; Vogel et al. 1997). Initial evidence for crosstalk between ECM and GF-induced signaling has been presented for different vertebrate cells (summarized by Schwartz 1995). However, the level at which this crosstalk occurs is still unclear. A direct association between an integrin receptor mediating cell attachment with activated insulin and PDGF- $\beta$ receptors has been demonstrated in fibroblasts (Schneller et al. 1997). A convergence in signaling may also occur at any later step of signal transduction. To address these questions for Aplysia BCNs requires an analysis of the basic mechanisms involved in substrate attachment and outgrowth of these cells.

\section{APLYSIA BCNS USE INTEGRIN-DEPENDENT AND RGD-DEPENDENT MECHANISMS FOR SUBSTRATE ATTACHMENT}

To analyze potential mechanisms of the interaction between BCNs and ECM, we used two different tools: antibodies to the extracellular domain of the $\beta 1$-subunit of integrin receptors, which should interfere with $\beta 1$-integrin-dependent adhesion and outgrowth, and RGD peptides. It is known that some integrins adhere to the RGD sequence that is found in laminin, fibronectin, and collagen (Yamada 1991; Ruoslahti 1996). Peptides containing this RGD sequence can be used to block cellular adhesion to RGD sequences within substrata. Similar to integrins, RGD sequences may be involved not only in adhesion but also in the promotion of neurite outgrowth (Tashiro et al. 1991). Although in many cases integrins bind to RGD sequences, both moieties also interact with other partners: Depending on the composition of the integrin heterodimer, diverse sequences in the same or different ECM molecules can be used for binding (Yamada 1991; Ruoslahti 1996). RGD sequences have also been reported to interact with nonintegrin cellular receptors (Goodman et al. 1991; Yamada 1991).

Interestingly, in our experiments antibodies to the $\beta 1$-subunit of integrins exclusively inhibited the attachment of BCNs to fibronectin (Fig. 7). However, the lack of effect on attachment to the other substrata does not necessarily indicate that attachment is integrin independent in these cases. Alternatively, different integrins that do not interact with the antibody we used may be involved in attachment to laminin and collagen. In contrast to the integrin antibody, the RGD peptides RGD and GRGDSP inhibited attachment to laminin and polyL-lysine, whereas a control peptide, GRGESP, did not compromise adhesion at all. Thus, adhesion of BCNs to fibronectin does not use the RGD site, possibly because this site is not sterically accessible in our cell culture system. On the other hand, laminin may act either via an integrin-independent but RGD-dependent mechanism, or it may use an integrin receptor that is different from the fibronectin receptor in BCNs for the interaction with RGD. Interestingly, Wildering et al. (1998) find that different mechanisms mediate the attachment of Lymnaea motor neurons to different vertebrate ECM molecules. In their system, attachment to fibronectin but not to laminin or collagen uses an RGD-dependent mechanism. Finally, the mechanism for attachment of BCNs to collagen must be different from the adhesion to laminin and fibronectin and seems to require neither integrins nor RGD. One possible explanation could be the existence of a tyrosine kinase collagen receptor in Aplysia similar to the discoidin receptor tyrosine ki-

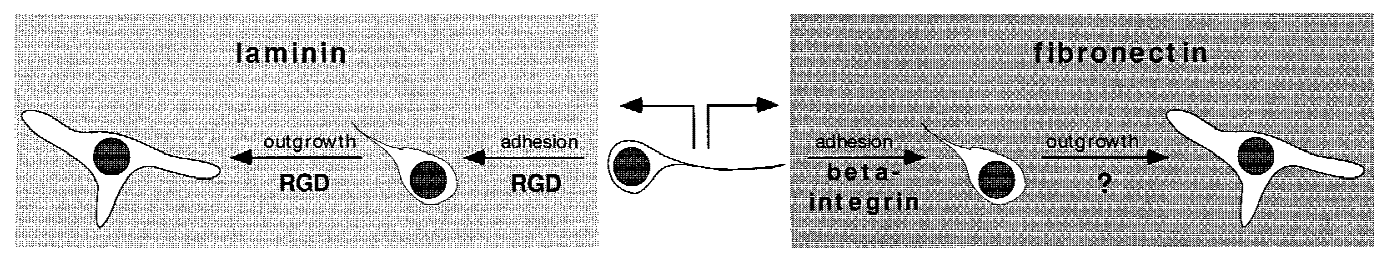

Figure 11: Schematic drawing illustrating that mechanisms of $\mathrm{BCN}$ adhesion and neurite outgrowth depend on the substrate. Whereas adhesion to laminin is mediated by an RGD-dependent, but integrin-independent, mechanism (Left), adhesion to fibronectin requires an RGD-independent, integrin-dependent process (Right). Interestingly, in the case of laminin, an RGD-dependent mechanism is used not only for adhesion but also for neurite outgrowth. In contrast, outgrowth on fibronectin requires a mechanism (as yet uncharacterized) that is different from the adhesion mechanism and is integrin- and RGD-independent

$$
\text { ………面 }
$$


nases in vertebrates (Shrivastava et al. 1997; Vogel et al. 1997). These kinases possess a domain with high homology to the discoidin I protein expressed in the slime mold Dictyostelium discoideum. Discoidin $I$ is a lectin that is involved in substrate adhesion and cell aggregation during the development of this organism. It is somewhat surprising that RGD peptides inhibit adhesion to poly-L-lysine, which is not a physiological ECM substrate. However, RGD peptides still exert specific effects in our system, as attachment to neither collagen nor fibronectin is compromised by RGD.

\section{MECHANISMS USED FOR ADHESION AND NEURITE OUTGROWTH OF BCNS ARE SUBSTRATE SPECIFIC}

In addition to the effects on adhesion, we also observed effects of the $\beta 1$-integrin antibody and the RGD peptides on BCN morphology. Surprisingly, the $\beta 1$-integrin antibody modulated $\mathrm{BCN}$ morphology in a pattern very similar to the effects of CNTF: Although not changing neurite outgrowth, the $\beta 1$-integrin antibody led to an enlargement of soma diameter on laminin and fibronectin and a reduction on collagen. One speculation arising from these observations is that CNTF might act on BCNs via an inhibitory interaction with an integrin receptor. RGD peptides, on the other hand, did not change the soma diameter of BCNs but selectively decreased neurite outgrowth on laminin. Thus, in the case of laminin, similar mechanisms are used for BCN attachment and outgrowth, whereas for fibronectin these mechanisms clearly differ (illustrated in Fig. 11). Finally, at present the mechanisms for both attachment and outgrowth of BCNs on collagen remain unknown.

In summary, our data suggest that Aplysia BCNs use different, substrate-specific mechanisms for attachment and outgrowth on ECM substrata. ECM itself induces signaling processes in BCNs and thereby modulates the response of these cells to different GFs. The challenge now is to analyze ECM and GF-induced signaling cascades and to identify points of convergence between both pathways. Moreover, because GFs can exert long-lasting changes in synaptic efficacy in Aplysia sensory neurons (Zhang et al. 1997) and because long-term facilitation in these neurons is accompanied by clear patterns of neurite growth (Bailey and Kandel 1993), it will be intriguing to explore the possibility that some of the structural changes induced by GFs that we observe in the present paper might also accompany long-term changes in synaptic ef- ficacy induced in the sensory neurons by neurotrophic modulators.

\section{Acknowledgments}

This work was supported by a Feodor Lynen Fellowship awarded to L.M.G. and by National Institute of Mental Health grant RO1 MH-14-1083 to T.J.C. We thank Haig Keshishian for his help with the confocal microscopy and Sharen McKay, Carolyn Sherff, and Angela Purcell for their very helpful comments on an earlier draft of the manuscript. The publication costs of this article were defrayed in part by payment of page charges. This article must therefore be hereby marked "advertisement" in accordance with 18 USC section 1734 solely to indicate this fact.

\section{References}

Bailey, C.H. and E.R. Kandel. 1993. Structural changes accompanying memory storage. Annu. Rev. Physiol. 55: 397-426.

Barde, Y.-A. 1990. The nerve growth factor family. Prog. Growth Factor Res. 2: 237-248.

Bogaert, T., N. Brown, and M. Wilcox. 1987. The Drosophila PS2 antigen is an invertebrate integrin that, like the fibronectin receptor, becomes localized to muscle attachments. Cell 51: 929-940.

Bulloch, A.G.M., N.I. Syed, and R.L. Ridgway. 1994. Neurite outgrowth and synapse formation by Lymnaea neurons: Towards a characterization of molluscan neurotrophic factors. Netherlands J. Zool. 44:(3-4) 317-326.

Bunch, T.A. and D.L. Brower. 1992. Drosophila PS2 integrin mediates RGD-dependent cell-matrix interactions. Development 116: 239-247.

Carter, B.D. and G.R. Lewin. 1997. Neurotrophins live or let die: Does p75 NTR decide? Neuron 18: 187-190.

Cox, G.N. 1992. Molecular and biochemical aspects of nematode collagens. J. Parasitol. 78: 1-15.

Davies, A.M. 1997. Neurotrophins: The yin and yang of nerve growth factor. Curr. Biol. 7: R38-R40.

de Curtis, I. 1991. Neuronal interactions with the extracellular matrix. Curr. Opin. Cell Biol. 3: 824-831.

Fainzilber, M., A.B. Smit, N.I. Syed, W.C. Wildering, P.M. Hermann, R.C. van der Schors, C. Jimenez, K.W. Li, J. van Minnen, A.G.M. Bulloch, C.F. Ibanez, and W.P.M. Geraerts. 1996. CRNF, a molluscan neurotrophic factor that interacts with the p75 neurotrophin receptor. Science 274: 1540-1543.

Fessler, J.H. and L.I. Fessler. 1989. Drosophila extracellular matrix. Annu. Rev. Cell Biol. 5: 309-339.

Gettner, S.N., C. Kenyon, and L.F. Reichardt. 1995.

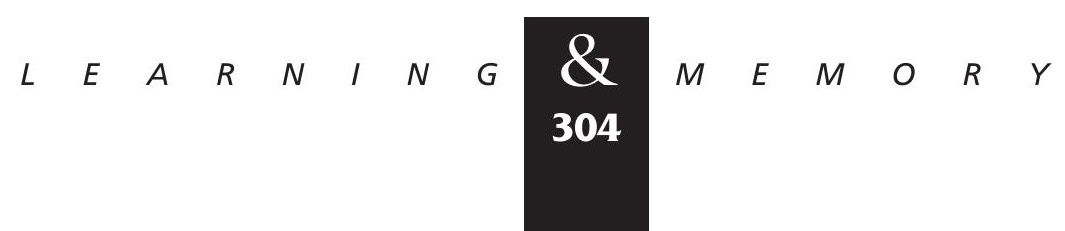


Characterization of $\beta$ pat- 3 heterodimers, a family of essential integrin receptors in C. elegans. J. Cell Biol. 129: 1129-1141.

Goodman, S.L., M. Aumailley, and H. von der Mark. 1991. Multiple cell surface receptors for the short arms of laminin: alpha1 beta1 integrin and RGD-dependent proteins mediate cell attachment only to domains III in murine tumor laminin. J. Cell Biol. 113 : 931-941.

Gratecos, D., C. Naidet, M. Astier, J.P. Thiery, and M. Semeriva. 1988. Drosophila fibronectin: A protein that shares properties similar to those of its mammalian homologue. EMBO J. 7: 215-223.

Haas, T.A. and E.F. Plow. 1994. Integrin-ligand interactions: A year in review. Curr. Opin. Cell. Biol. 6: 656-662.

Har-El, R. and M.L. Tanzer. 1993. Extracellular matrix 3: Evolution of the extracellular matrix in invertebrates. FASEB J. 7: 1115-1123.

Hayashi, I., M. Perez-Magallanes, and J.M. Rossi. 1992. Neurotrophic factor-like activity in Drosophila. Biochem. Biophys. Res. Commun. 184: 73-79.

Iwata, M. and E. Nakano. 1981. Fibronectin from ovary of the sea urchin, Pseudocentrotus depressus. Wilhelm Roux's Arch. Dev. Biol. 190: 83-86.

Jonas, E.A., R.J. Knox, L.K. Kaczmarek, J.H. Schwartz., and D.H. Solomon. 1996. Insulin receptor in Aplysia neurons: Characterization, molecular cloning, and modulation of ion currents. J. Neurosci. 16: 1645-1658.

Kaczmarek, L.K., M. Finbow, J.P. Revel, and F. Strumwasser. 1979. The morphology and coupling of Aplysia bag cells within the abdominal ganglion and in cell culture. J. Neurobiol. 10: 535-550.

Kang, H. and E.M. Schuman. 1995. Long-lasting neurotrophin-induced enhancement of synaptic transmission in the adult hippocampus. Science 273: 1402-1406.

Korsching, S. 1993. The neurotrophic factor concept: A re-examination. J. Neurosci. 13: 2739-2748.

Korte, M., C. Carrol, E. Wolf, G. Brehm, H. Thoenen, and T. Bonhoeffer. 1995. Hippocampal long-term potentiation is impaired in mice lacking brain-derived neurotrophic factor. Proc. Natl. Acad. sci. 92: 8856-8860.

Levi-Montalcini, R. 1987. The nerve growth factor 35 years later. Science 237: 1154-1161.

Marcantonio, E.E. and R.O. Hynes. 1988. Antibodies to the conserved cytoplasmic domain of the integrin $\beta 1$ subunit react with proteins in vertebrates, invertebrates, and fungi. J. Cell Biol. 106: 1765-1772.

Masuda-Nakawaga, L., K. Beck, and M. Chiquet. 1988. Identification of molecules in leech extracellular matrix that promote neurite outgrowth. Proc. R. Soc. Lond. B. Biol. Sci. 235: $245-257$.
Mattson, M.P. and S.B. Kater. 1988. Fibronectin-like immunoreactivity in Helisoma buccal ganglia: Evidence that an endogenous fibronectin-like molecule promotes neurite outgrowth. J. Neurobiol. 19: 239-256.

Mayford, M., A. Barzilai, F. Keller, S. Schacher, and E.R. Kandel. 1992. Modulation of an NCAM-related adhesion molecule with long-term synaptic plasticity in Aplysia. Science 256: 638-644.

McCarthy, R.A., K. Beck, and M.M. Burger. 1987. Laminin is structurally conserved in the sea urchin basal lamina. $E M B O$ J. 6: 1587-1595.

Patterson, S.L., T. Abel., T.A.S. Deuel, K.C. Martin, J.C. Rose, and E.R. Kandel. 1996. Recombinant BDNF rescues deficits in basal synaptic transmission and hippocampal LTP in BDNF knockout mice. Neuron 16: 1137-1145.

Pulido, D., S. Campuzano, T. Koda, J. Modolell, and M. Barbacid. 1992. Dtrk, a Drosophila gene related to the $t r k$ family of neurotrophin receptors, encodes a novel class of neural cell adhesion molecule. EMBO J. 11: 391-404.

Ridgway, R.L., N.I. Syed, K. Lukowiak, and A.G.M. Bulloch. 1991. Nerve growth factor (NGF) induces sprouting of specific neurons of the snail, Lymaea stagnalis. J. Neurobiol. 22: $377-390$.

Rogers, S.L., P.C. Letourneau, S.L. Palm, J. McCarthy, and L.T. Furcht. 1983. Neurite extension by peripheral and central nervous system neurons in response to substratum-bound fibronectin and laminin. Dev. Biol. 98: $212-220$.

Ruoslahti, E. 1996. RGD and other recognition sequences for integrins. Annu. Rev. Cell Dev. Biol. 12: 697-715.

Sarras, M.J., M. Madden, X.M. Zhang, S. Gunwar, J.K. Huff, and B.G. Hudson. 1991. Extracellular matrix (mesoglea) of Hydra vulgaris. I. Isolation and characterization. Dev. Biol. 148: 481-494.

Schacher, S. and E. Prohansky. 1983. Neurite regeneration by Aplysia neurons in dissociated cell culture: Modulation by Aplysia hemolymph and the presence of the initial axonal segment. J. Neurosci. 3: 2403-2413.

Schaller, M.D., C.A. Borgman, B.S. Cobb, R.R. Vines, A.B. Reynolds, and J.T. Parsons. 1992. PP125FAK, a structurally unique protein kinase associated with focal adhesions. Proc. Natl. Acad. Sci. 89: 192-196.

Schlaepfer, D.D., S.K. Hanks, T. Hunter, and P. van der Geer. 1994. Integrin-mediated signal transduction linked to Ras pathway by GRB2 binding to focal adhesion kinase. Nature 372: 786-791.

Schneller, M., K. Vuori, and E. Ruoslahti. 1997. $\alpha v \beta 3$ integrin associates with activated insulin and PDGF $\beta$ receptors and potentiates the biological activity of PDGF. EMBO J. 16: $5600-5607$.

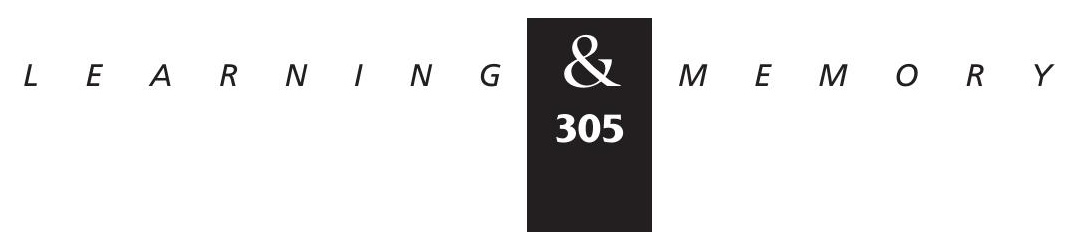




\section{Gruenbaum and Carew}

Schwartz, M.A., M.D. Schaller, and M.H. Ginsberg. 1995. Integrins: Emerging paradigms of signal transduction. Annu. Rev. Cell Dev. Biol. 11: 549-599.

Shimizu, K., S. Amemiya, and K. Yoshizato. 1990. Biochemical and immunological characterization of collagen molecules from echinothurioid sea urchin Asthenosoma ijimai. Biochim. Biophys. Acta 1038: 39-46.

Shrivastava, A., C. Radziejewski, E. Campbell, L. Kovac, M. McGlynn, T.E. Ryan, S. Davis., P. Goldfarb, D.J. Glass, G. Lemke, and G.D. Yancopoulos. 1997. An orphan receptor tyrosine kinase family whose members serve as nonintegrin collagen receptors. Mol. Cell 1: 25-34.

Springer, W.R., D.N.W. Cooper, and S.H. Barondes. 1984. Discoidin I is implicated in cell-substratum attachment and ordered cell migration of Dictyostelium discoideum and resembles fibronectin. Cell 39: 557-564.

Stahl, N. and G.D. Yancopoulos. 1994. The tripartite CNTF receptor complex: Activation and signalling involves components shared with other cytokines. J. Neurobiol. 25: $1454-1466$.

Suter, D.M., L.D. Errante, V. Belotserkovsky, and P. Forscher. 1998. The Ig superfamily cell adhesion molecule, apCAM, mediates growth cone steering by substrate-cytoskeletal coupling. J. Cell Biol. 141: 227-240.

Syed, N., P. Richardson, and A. Bulloch. 1996. Ciliary neurotrophic factor, unlike nerve growth factor, supports neurite outgrowth but not synapse formation by adult Lymnaea neurons. J. Neurobiol. 29: 293-303.

Tashiro, K., G.C. Sephel, D. Greatorex, M. Sasaki, N. Shirashi, G.R. Martin, H.K. Kleinman, and Y. Yamada. 1991. The RGD containing site of the mouse laminin A chain is active for cell attachment, spreading, migration and neurite outgrowth. J. Cell. Physiol. 146: 451-459.

Tomaselli, K.J., C.H. Damsky, and L.F. Reichardt. 1987. Interactions of a neuronal cell line (PC12) with laminin, collagen IV, and fibronectin: Identification of integrin-related glycoproteins involved in attachment and process outgrowth. J. Cell Biol. 105: 2347-2358.

Treubert, U. and T. Bruemmendorf. 1998. Functional cooperation of $\beta 1$-integrins and members of the Ig superfamily in neurite outgrowth induction. J. Neurosci. 18: 1795-1805.

Vogel, W., G.D. Gish, F. Alves, and T. Pawson. 1997. The discoidin domain receptor tyrosine kinases are activated by collagen. Mol. Cell 1: 13-23.

Wildering, W.C., P.M. Hermann, and A.G.M. Bulloch. 1998. Neurite outgrowth, RGD-dependent, and RGD-independent adhesion of identified molluscan motoneurons on selected substrates. J. Neurobiol. 35: 37-52.

Wu, D., L. Wang, C.A. Mason, and D.J. Goldberg. 1996. Association of $\beta 1$-integrin with phosphotyrosine in growth cone filopodia. J. Neurosci. 16: 1470-1478.
Yamada, K.M. 1991. Adhesive recognition sequences. J. Biol. Chem. 266: 12809-12812.

Zhang, F., S. Endo, L.J. Cleary, A. Eskin, and J.H. Byrne. 1997. Role of transforming growth factor- $\beta$ in long-term synaptic facilitation in Aplysia. Science 275: 1318-1320.

Ziegler, U. and R.P. Stidwill. 1992. The attachment of nematocytes from the primitive invertebrate Hydra to fibronectin is specific and RGD-dependent. Exp. Cell Res. 202: 281-286.

Received April 2, 1999; accepted in revised form June 8, 1999. 


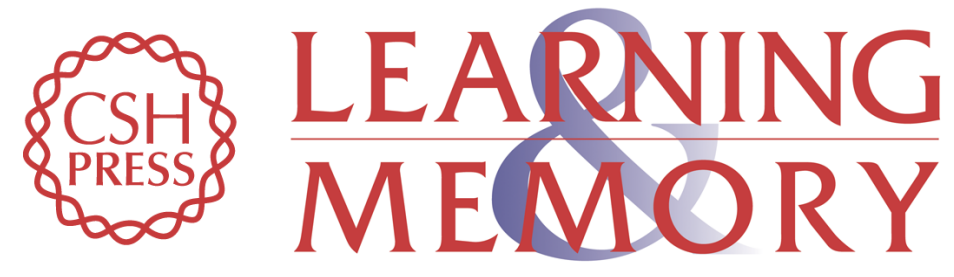

\section{Growth Factor Modulation of Substrate-Specific Morphological Patterns in Aplysia Bag Cell Neurons}

Lore M. Gruenbaum and Thomas J. Carew

Learn. Mem. 1999, 6:

Access the most recent version at doi:10.1101//m.6.3.292

References This article cites 55 articles, 19 of which can be accessed free at: http://learnmem.cshlp.org/content/6/3/292.full.html\#ref-list-1

License

Email Alerting Receive free email alerts when new articles cite this article - sign up in the box at the Service top right corner of the article or click here. 